\title{
ON A STURM-LIOUVILLE TYPE DIFFERENTIAL INCLUSION OF FRACTIONAL ORDER
}

\author{
Aurelian CERnEA
}

Abstract. The existence of solutions for a Sturm-Liouville type differential inclusion of fractional order is investigated. New results are obtained by using suitable fixed point theorems when the right hand side has convex or non convex values.

Mathematics subject classification (2010): 34A60.

Keywords and phrases: Differential inclusion, measurable selection, fractional derivative.

\section{REFERENCES}

[1] A. Bressan And G. Colombo, Extensions and selections of maps with decomposable values, Studia Math. 90, (1988), 69-86.

[2] M. CAPuto, Elasticità e Dissipazione, Zanichelli, Bologna, 1969.

[3] A. CERneA, Continuous selections of solutions sets of fractional integrodifferential inclusions, Acta Math. Sci. 35B, (2015), 399-406.

[4] A. CerneA, On a fractional differential inclusion with "maxima”, Fract. Calc. Appl. Anal. 19, (2016), $1292-1305$.

[5] H. COVITZ AND S. B. NADLER JR., Multivalued contraction mapping in generalized metric spaces, Israel J. Math. 8, (1970), 5-11.

[6] K. Diethelm, The Analysis of Fractional Differential Equations, Springer, Berlin, 2010.

[7] M. FRIGNON AND A. GRANAS, Théorèmes d'existence pour les inclusions différentielles sans convexité, C. R. Acad. Sci. Paris, Ser. I 310, (1990), 819-822.

[8] S. R. Grace, J. R. GRAeF And E. Tunc, Asymptotic behavior of solutions of forced fractional differential equations, Electronic J. Qual. Theory Differ. Equations 2016, no. 71, (2016), 1-10.

[9] J. R. GRAEF, S. R. GRACE AND E. TUNC, Asymptotic behavior of solutions of nonlinear fractional differential equations with Caputo-type Hadamard derivatives, Fract. Calc. Appl. Anal. 20, (2017), 71-87.

[10] J. R. Graef, S. R. Grace And E. Tunc, On the oscillation of certain integral equations, Publ. Math. Debrecen 90, (2017), 195-204.

[11] A. A. Kilbas, H. M. SRivastava And J. J. Trujillo, Theory and Applications of Fractional Differential Equations, Elsevier, Amsterdam, 2006.

[12] A. LASOTA AND Z. OPIAL, An application of the Kakutani-Ky-Fan theorem in the theory of ordinary differential equations, Bull. Acad. Polon. Sci. Math., Astronom. Physiques 13, (1965), 781-786.

[13] L. Piccini, G. Stampacchia and G. Vidossich, Equazioni Differenziali in $R^{n}$, Ligouri, Napoli, 1978.

[14] D. O'Regan, Fixed point theory for closed multifunctions, Arch. Math. (Brno), 34, (1998), 191-197.

[15] I. Podlubny, Fractional Differential Equations, Academic Press, San Diego, 1999.

[16] J. WANG, A. G. IBRAHIMAND AND M. FeČKAN, Differential inclusions of arbitrary fractional order with anti-periodic conditions in Banach spaces, Electronic J. Qual. Theory Differ. Equations 2016, no. 34, (2016), 1-22. 